\title{
STATUS GIZI, VENTILASI, KEBIASAAN MEROKOK DAN PERAN TENAGA KESEHATAN DENGAN KEJADIAN TB PARU
}

\author{
RELATIONSHIP BETWEEN NUTRITIONAL STATUS, \\ VENTILATION, SMOKING HABITS AND THE ROLE OF \\ HEALTH WORKERS WITH PULMONARY TUBERCULOSIS
}

\author{
Neila Sulung ${ }^{1}$ Nunung Gus Amalia ${ }^{2}$ \\ ${ }^{2}$ Sekolah Tinggi Ilmu Kesehatan (STIKes) Fort De Kock Bukittinggi, \\ Jalan Sukarno Hatta Bukittinggi telp: 0752; 31877 dan HP.085365658494 \\ Email: neilasulung@fdk.ac.id
}

\begin{abstract}
Tuberculosis (TB) is still a major health problem. In 2017, 36 cases of Tuberculosis were recorded in the work area of Rasimah Ahmad Public Health Center in Bukittinggi, which is the highest number of all Health Center. The aim of the study was to determine the relationship of nutritional status, ventilation, smoking habits and the role of health workers with the incidence of pulmonary TB. This study uses an observational method with a case control approach. There are 2 populations consisting of 36 case populations and 36 control populations with total sampling and purposive sampling techniques with a sample ratio of 1: 1. Data analysis was performed using univariate and bivariate analysis. The results of the study obtain that there was a relationship between nutritional status (pvalue $=0,000, O R=9,416$ ), smoking habits ( $p$ value $=0,008, O R=4,375$ ) and the role of health workers ( $p$ value $=0,000, O R=$ 7,000). And there was also no correlation between ventilation and the incidence of pulmonary tuberculosis (pvalue $=1,000$ and $O R=1,000$ ). Conclusion variables that have a lot of chance of risk for the incidence of pulmonary TB are nutritional status. It is recommended to maintain the diet by eating according to nutritional needs and regularly.

Keywords: Smoking, Pulmonary TB, Health Workers, Nutritional, Ventilation
\end{abstract}

\begin{abstract}
ABSTRAK
Tuberkulosis (TB) masih menjadi masalah kesehatan utama. Tahun 2017 tercatat 36 kasus Tuberkulosis di wilayah kerja Puskesmas Rasimah Ahmad Kota Bukittinggi yang angka ini merupakan angka tertinggi dari seluruh Puskesmas. Tujuan penelitian untuk mengetahui hubungan status gizi, ventilasi, kebiasaan merokok dan peran tenaga kesehatan dengan kejadian TB Paru. Penelitian ini menggunakan metode observational dengan pendekatan case control terdapat 2 populasi terdiri dari populasi kasus sebanyak 36 dan populasi kontrol 36 dengan teknik total sampling dan purposive sampling dengan perbandingan sampel 1:1. Analisis data dilakukan secara analisis univariat dan bivariate. Dari hasil penelitian bahwa terdapat hubungan antara status gizi (pvalue $=0,000, \mathrm{OR}=9,416$ ), kebiasaan merokok (pvalue $=0,008$, $\mathrm{OR}=4,375$ ) dan peran tenaga kesehatan (pvalue $=0,000, \mathrm{OR}=7,000)$. Dan juga tidak terdapat hubungan antara ventilasi dengan kejadian TB paru, (pvalue $=1,000$ dan $\mathrm{OR}=1,000$ ). Kesimpulan, variabel yang banyak memiliki peluang resiko untuk kejadian TB paru adalah status gizi. Disarankan untuk menjaga pola makan dengan makan sesuai kebutuhan zat gizi dan teratur.
\end{abstract}

Kata kunci: Gizi, Merokok, TB Paru, Tenaga Kesehatan, Ventilasi

PENDAHULUAN

Tuberkulosis

(TB) masih

menjadi masalah kesehatan utama di dunia. Tuberkulosis (TB) adalah suatu penyakit infeksi menular yang disebabkan oleh bakteri Mycobacterium tuberculosis, yang dapat menyerang berbagai organ, terutama paru-paru. 
Penyakit ini bila tidak diobati atau pengobatannya tidak tuntas dilakukan dapat menimbulkan komplikasi yang berbahaya hingga kematian (Infodatin, 2016).

Indonesia merupakan negara dengan jumlah kasus baru tuberkulosis terbanyak kedua di dunia setelah India. Sebesar 60\% kasus baru terjadi di 6 negara yaitu India, Indonesia, China, Nigeria, Pakistan dan Afrika Selatan. Kematian akibat tuberkulosis diperkirakan sebanyak 1,4 juta kematian ditambah 0,4 juta kematian akibat tuberkulosis pada penderita HIV. Meskipun jumlah kematian akibat tuberkulosis menurun $22 \%$ antara tahun 2000 dan 2015, tuberkulosis tetap menjadi 10 penyebab kematian tertinggi di dunia pada tahun 2015 (WHO, Global Tuberculosis Report, 2016). Pada tahun 2016 ditemukan jumlah kasus tuberkulosis sebanyak 351.893 kasus, meningkat bila dibandingkan semua kasus tuberkulosis yang ditemukan pada tahun 2015 yang sebesar 330.729 kasus (Profil Kesehatan Indonesia, 2016).

Berdasarkan teori yang ada bahwa kontak serumah merupakan factor yang dapat meningkatkan resiko penular Tubercolosis (Nurhidayah dkk 2007, p.15).

Berdasarkan Laporan Dinas Kesehatan di Provinsi Sumatera Barat, angka insidensi semua tipe kasus tuberkulosis dan kasus baru tuberkulosis BTA Positif sebesar 131,65 per 100.000 penduduk atau sekitar 6.603 kasus semua tipe tuberkulosis, insidensi kasus baru tuberkulosis BTA Positif sebesar 102,35 per 100.000 penduduk atau sekitar 4.790 kasus baru tuberkulosis BTA Positif. Di Provinsi Sumatera Barat, Kota Bukittinggi termasuk kedalam urutan ke-10 kejadian tuberkulosis terbanyak dengan rincian nya yaitu Kota Padang 1.710 kasus, Kabupaten Pesisir Selatan 866 kasus, Kabupaten Padang Pariaman 714 kasus, Kabupaten Pasaman Barat 513 kasus, Kabupaten Pasaman 418 kasus, Kabupaten Lima Puluh Kota 385 kasus, Kabupaten Dharmasraya 276 kasus, Kabupaten Solok Selatan 274 kasus, Kota Solok 274 kasus, dan Kota Bukittinggi 238 kasus (Profil Dinas Kesehatan Prov.Sumbar, 2015).

Di Kota Bukittinggi, penyakit Tuberkulosis paru merupakan salah satu target pemberantasan penyakit menular karena Tuberkulosis paru merupakan kasus kejadian penyakit yang cukup 
tinggi. Pada tahun 2014 jumlah kasus penderita tuberkulosis di Kota Bukittinggi sebanyak 231 kasus per 100.000 penduduk, dengan jumlah kasus tertinggi berada di wilayah kerja Puskesmas Perkotaan Rasimah Ahmad yaitu sebanyak 21 kasus dari jumlah kasus baru, sedangkan pada tahun 2015 tercatat sebanyak 239 kasus dengan jumlah kasus tertinggi yaitu sebanyak 15 kasus di wilayah kerja Puskesmas Rasimah Ahmad dan pada tahun 2016 tercatat 9 kasus Tuberkulosis paru di wilayah kerja Puskesmas Rasimah Ahmad yang angka ini merupakan angka tertinggi dari seluruh Puskesmas.

Kemudian menurut laporan Dinas Kesehatan Kota Bukittinggi pada tahun 2017 jumlah selurus kasus Tuberkulosis paru adalah 110 kasus, dengan jumlah kasus terbanyak juga terdapat di wilayah kerja Puskesmas Rasimah Ahmad yaitu 36 kasus dan kasus paling sedikit terdapat di wilayah kerja Puskesmas Gulai Bancah yaitu 4 kasus.

Berdasarkan permasalahan yang ditemukan diatas, maka peneliti tertarik dengan tujuan melakukan penelitian tentang hubungan status gizi, ventilasi, kebiasaan merokok dan peran petugas kesehatan dengan kejadian Tuberkulosis paru di wilayah kerja Puskesmas Rasimah Ahmad Tahun 2018.

\section{METODOLOGI}

Penelitian ini menggunakan studi observational analitik dengan jenis desain penelitian studi kasus kontrol (case control study). Case control yaitu penelitian yang menentukan penyakit (outcome) terlebih dahulu kemudian mengidentifikasi penyebab (faktor resiko) Notoatmodjo, S. (2007). Penelitian ini dilaksanakan di wilayah kerja Puskesmas Rasimah Ahmad dari tanggal 14-16 Agustus 2018.

Populasi pada penelitian ini terdapat 2 populasi yaitu populasi kasus adalah seluruh penderita TB paru di wilayah kerja Puskesmas Rasimah Ahmad dan populasi kontrol adalah kontak serumah dengan penderita TB paru yang masing-masing berjumlah 36 . Dengan teknik pengambilan sampel total sampling dan purposive sampling dengan perbandingan sampel 1:1. Jadi sampel pada penelitian ini berjumlah 72. dengan memilih sampel berdasarkan kriteria tertentu yang telah ditetapkan peneliti. Kelompok kontrol dalam penelitian ini adalah kontak serumah dengan penderita TB paru. 
HASIL DAN PEMBAHASAN

Tabel 1. Perbandingan antara Kasus dan Kontrol

\begin{tabular}{clcc}
\hline No & $\begin{array}{c}\text { Kejadian } \\
\text { Tuberkulosis Paru }\end{array}$ & f & \% \\
\hline 1. & Kasus & 36 & 50 \\
\hline 2. & Kontrol & 36 & 50 \\
\hline & Total & 72 & 100
\end{tabular}

Sumber: Hasil Penelitian di Puskesmas Rasimah Ahmad Kota Bukittinggi2018

Berdasarkan tabel 1. Didapatkan perbandingan antara kasus dan kontrol sebanyak 1:1 dengan jumlah 72 respoden di Wilayah kerja Puskesmas Rasimah Ahmad

Tabel 2. Analisis Univariat Distribusi Frewensin Variabel, Stustus Gizi. Ventilasi, Kebiasaan Merokok, Peran tenaga Kesehatan

\begin{tabular}{|c|c|c|c|c|}
\hline \multirow{3}{*}{ Variabel } & \multicolumn{4}{|c|}{ Kejadian TB Paru } \\
\hline & \multicolumn{2}{|c|}{ Kasus } & \multicolumn{2}{|c|}{ Kontrol } \\
\hline & $f$ & $\%$ & $f$ & $\%$ \\
\hline \multicolumn{5}{|l|}{ Status Gizi } \\
\hline Kurang & 25 & 69,4 & 7 & 19,4 \\
\hline Cukup & 11 & 30,6 & 29 & 80,6 \\
\hline Total & 36 & 100 & 36 & 100 \\
\hline \multicolumn{5}{|l|}{ Ventilasi } \\
\hline $\begin{array}{l}\text { Tidak memenuhi } \\
\text { syarat }\end{array}$ & 23 & 63,9 & 23 & 63,9 \\
\hline Memenuhi syarat & 13 & 39,1 & 13 & 39,1 \\
\hline Total & 36 & 100 & 36 & 100 \\
\hline \multicolumn{5}{|l|}{ Kebiasaan Merokok } \\
\hline $\begin{array}{l}\text { Merokok jika } \geq 6 \\
\text { bulan }\end{array}$ & 28 & 77,8 & 16 & 44,4 \\
\hline Tidak merokok & 8 & 22,2 & 20 & 55,6 \\
\hline Total & 36 & 100 & 36 & 100 \\
\hline \multicolumn{5}{|l|}{ Peran Tenaga } \\
\hline Kurang baik & 24 & 66,7 & 22 & 61,1 \\
\hline Baik & 12 & 33,3 & 14 & 38,9 \\
\hline Total & 36 & 100 & 36 & 100 \\
\hline Kejadian TB Paru & 36 & 50 & 36 & 50 \\
\hline
\end{tabular}

Hasil Pengumpulan data: Puskesmas Rasimah Ahmad Kota Bukittinggi

Dari 72 responden, diperoleh status gizi yang paling banyak adalah status gizi cukup sebanyak 29 responden $(80,6 \%)$ pada kelompok kontrol. Kondisi ventilasi responden lebih banyak yang tidak memenuhi syarat yaitu sebanyak 23 responden $(63,9 \%)$ baik pada kelompok kasus maupun pada kelompok kontrol. Kebiasaan merokok pada responden lebih banyak yang merokok $\geq 6$ bulan sebanyak 28 responden $(77,8 \%)$ pada kelompok kasus. Peran tenaga kesehatan lebih banyak yang kurang baik sebanyak 24 responden $(66,7 \%)$ pada kelompok kasus.

Tabel 3. Analisis Bivariat Hubungan, Stustus Gizi. Ventilasi, Kebiasaan Merokok, Peran tenaga Kesehatan dengan Kejadian TB Paru

\begin{tabular}{|c|c|c|c|c|c|c|}
\hline \multirow{3}{*}{ Variabel } & \multicolumn{4}{|c|}{ Kejadian TB Paru } & \multirow{3}{*}{$\begin{array}{c}\mathbf{P} \\
\text { value }\end{array}$} & \multirow{3}{*}{ OR } \\
\hline & \multicolumn{2}{|c|}{ Kasus } & \multicolumn{2}{|c|}{ Kontrol } & & \\
\hline & $\mathrm{n}$ & $\%$ & $\mathrm{n}$ & $\%$ & & \\
\hline \multicolumn{7}{|l|}{ Status gizi } \\
\hline Kurang & 25 & 69,4 & 7 & 19,4 & 0,000 & 9,416 \\
\hline Cukup & 11 & 30,6 & 29 & 80,6 & & \\
\hline Total & 36 & 100 & 36 & 100 & & \\
\hline \multicolumn{7}{|l|}{ Ventilasi } \\
\hline Tidak & 23 & 63,9 & 23 & 63,9 & & \\
\hline i syarat & & & & & 1,000 & 1,000 \\
\hline $\begin{array}{l}\text { Memenuh } \\
\text { i syarat }\end{array}$ & 13 & 36,1 & 13 & 36,1 & & \\
\hline Total & 36 & 100 & 36 & 100 & & \\
\hline \multicolumn{7}{|l|}{$\begin{array}{l}\text { Kebiasaan } \\
\text { Merokok }\end{array}$} \\
\hline $\begin{array}{l}\text { Merokok } \\
\text { jika } \geq 6 \\
\text { bulan }\end{array}$ & 28 & 77,8 & 16 & 44,4 & 0,008 & 4,375 \\
\hline $\begin{array}{l}\text { Tidak } \\
\text { merokok }\end{array}$ & 8 & 22,2 & 20 & 55,6 & & \\
\hline Total & 36 & 100 & 36 & 100 & & \\
\hline \multicolumn{7}{|l|}{$\begin{array}{l}\text { Peran } \\
\text { Nakes }\end{array}$} \\
\hline $\begin{array}{l}\text { Kurang } \\
\text { baik }\end{array}$ & 24 & 66,7 & 8 & 22,2 & 0,000 & 7,000 \\
\hline Baik & 12 & 33,3 & 28 & 77,8 & & \\
\hline Total & 36 & 100 & 36 & 100 & & \\
\hline
\end{tabular}

Hasil Pengumpulan data: Puskesmas Rasimah Ahmad Kota Bukittinggi 
Hasil analisis bivariat dengan uji chi square menemukan bahwa variabel independen yang memiliki hubungan yang bermakna dengan kejadian TB Paru dengan nilai $\mathrm{p} \leq 0,05$ adalah status gizi, kebiasaan merokok dan peran tenaga kesehatan, sedangkan yang tidak memiliki hubungan adalah ventilasi.

\section{PEMBAHASAN}

\section{Status Gizi}

Lebih dari sebagian responden pada kelompok kasus memiliki status gizi kurang dibandingkan dengan kelompok kontrol. Hal ini menunjukkan bahwa status gizi kurang cenderung untuk terjadinya Tuberkulosis Paru. Status gizi adalah salah satu faktor penting dalam pertahanan tubuh terhadap infeksi Tuberkulosis paru. Penelitian ini tidak sejalan dengan penelitian yang dilakukan oleh (Dina Mariana, 2017) tentang kepadatan hunian, ventilasi dan pencahayaan terhadap kejadian TB paru di wilayah kerja Puskesmas Binanga Kabupaten Mamuju Sulawesi Barat bahwa jumlah kasus pada kejadian TB paru sebanyak 31 responden (33,33\%). Kelompok kasus pada penelitian ini adalah pasien yang menderita TB Paru dan kelompok kontrol adalah masyarakat yang tidak menderita TB Paru dan berdomisili di dekat rumah penderita TB Paru.
Penelitian ini sejalan dengan penelitian (Yuniar \& Lestari, 2017) tentang hubungan status gizi dan pendapatan terhadap kejadian Tuberkulosis paru bahwa ada hubungan yang bermakna antara status gizi dengan kejadian Tuberkulosis paru dengan nilai pvalue= 0,028

Status gizi kurang dapat menurunkan kekebalan tubuh sehingga tubuh melemah dan tidak dapat mempertahankan diri dari infeksi. Maka kepada responden untuk lebih memperhatikan makanan yang dikonsumsi, pola makan yang teratur dan dapat meningkatkan pengetahuan gizi dengan mengakses berbagai infomasi tentang gizi melalui berbagai media.

\section{Ventilasi}

Lebih dari sebagian responden memiliki ventilasi rumah yang tidak memenuhi syarat, baik pada kelompok kasus maupun kelompok kontrol. Tetapi, hasil uji chisqure menunjukkan tidak ada hubungan yang bermakna antara kondisi ventilasi rumah dengan kejadian TB paru. Penelitian ini sejalan dengan penelitian yang dilakukan oleh (Ricardo, Heriyani, \& Khatimah, 2016) tentang hubungan kondisi ventilasi rumah dengan kejadian TB paru di wilayah kerja Puskesmas Kelayan 
Timur pada dari 30 responden kelompok kasus distribusi frekuensi tertinggi adalah kondisi ventilasi yang tidak memenuhi syarat pada responden sebanyak 29 responden $(96,67 \%)$ dan dari 30 responden kelompok kontrol diperoleh distribusi frekuensi tertinggi adalah jumlah kondisi ventilasi yang memenuhi syarat sebanyak 20 responden $(66,67 \%)$.

Penelitian ini juga di dukung oleh (Ricardo et al., 2016) tentang hubungan kondisi ventilasi rumah dengan kejadian TB paru di wilayah kerja Puskesmas Kelayan Timur bahwa ada hubungan yang bermakna antara kondisi ventilasi rumah dengan kejadian TB paru dengan nilai pvalue $=0,000$. Walaupun hasil penelitian ini tidak berhubungan tetapi kondisi ventilasi rumah dapat berpengaruh terhadap kejadian Tuberkulosis paru. Oleh karena itu, ventilasi berfungsi sebagai tempat mengeluarkan udara yang tercemar (bakteri, CO2) didalam rumah dan menggantinya dengan udara yang segar dan bersih atau untuk sirkulasi udara tempat masuknya cahaya matahari.

\section{Kebiasaan Merokok}

Lebih dari sebagian responden pada kelompok kasus memiliki kebiasaan merokok $\geq 6$ bulan hal ini menunjukkan bahwa responden dengan kebiasaan merokok $\geq 6$ bulan cenderung untuk terjadinya kejadian. Penelitian ini sejalan dengan penelitian yang dilakukan oleh (Budi \& Tuntun, 2013) tentang faktor-faktor yang berhubungan dengan kejadian Tuberkulosis Paru BTA Positif pada pasien rawat jalan di UPT Puskesmas Wonosobo Kabupaten Tanggamus bahwa dari 34 responden kelompok kasus distribusi frekuensi tertinggi adalah jumlah responden merokok $\geq 6$ bulan sebanyak 18 responden $(26,47 \%)$ dan dari 34 responden kelompok kontrol diperoleh distribusi frekuensi tertinggi adalah jumlah responden tidak merokok sebanyak 21 responden $(30,89 \%)$. Peneliti ini didukung oleh (Rahmayuli et al., 2018) tentang hubungan merokok dengan hasil pemeriksaan bakteriologis sputum pada pasien tuberkulosis paru kategori I di Puskesmas Teladan Kota Medan bahwa terdapat hubungan antara merokok dengan hasil pemeriksaan bakteriologis sputum pada pasien TB paru kategori I dengan nilai pvalue= 0,000. Penelitian (Nurwanti, 2016). tentang hubungan antara faktor pejamu (host) dan faktor lingkungan 
(environtment) dengan kejadian tuberkulosis.

Tuberkulosis (TB) paru, karena responden sudah terbiasa merokok secara terus menerus dan lebih dari 6 bulan, kandungan didalam rokok yang dikonsumsi oleh responden dalam jangka waktu lama seperti lebih dari 6 bulan dapat memicu timbulnya terjadinya kejadian Tuberkulosis (TB) paru. Dengan demikian, bagi masyarakat khususnya bagi responden agar memperhatikan bahaya merokok yang didapatkan baik dari penyuluhan yang diberikan oleh tenaga kesehatan, media massa maupun pada bungkus rokok.

\section{Peran Tenaga Kesehatan}

Lebih dari sebagian responden pada kelompok kasus dengan peran tenaga kesehatan kurang baik sedangkan lebih dari sebagian responden pada kelompok kontrol dengan peran tenaga kesehatan yang baik. Hal ini menunjukkan bahwa peran tenaga kesehatan yang kurang cenderung untuk terjadinya kejadian Tuberkulosis (TB) paru karena kurangnya perhatian dan dorongan dari tenaga kesehatan kepada responden terhadap kejadian Tuberkulosis (TB) paru. Penelitian ini sejalan dengan penelitian yang dilakukan oleh (Sari \& Arisandi, 2018) tentang faktor-faktor yang berhubungan dengan pencegahan penularan Tuberkulosis paru di Jorong Subarang Nagari Koto Baru wilayah kerja Puskesmas Selayo Kabupaten Solok bahwa dari 93 responden terdapat 50 responden $(53,8 \%)$ dengan peran tenaga kesehatan kurang baik karena lebih dari sebagian responden dengan peran tenaga kesehatan yang kurang baik dibandingkan dengan peran tenaga kesehatan yang baik. Penelitian ini juga sama dengan penelitian Maryani (2015) tentang hubungan tingkat pengetahuan petugas kesehatan tentang Tuberkulosis dengan peranan petugas kesehatan dalam penemuan suspek tuberkulosis di Puskesmas Kertasura bahwa ada hubungan yang bermakna antara peran petugas kesehatan dengan kejadian TB paru dengan nilai Pvalue $=0,00$.

Diharapkan kepada tenaga kesehatan dapat meningkatkan peran untuk lebih peduli dalam mengatasi kejadian Tuberkulosis (TB) paru sehingga kejadian Tuberkulosis (TB) paru dapat teratasi dengan baik.

\section{KESIMPULAN}

Diketahui perbandingan proporsi jumlah kasus pada kejadian TB Paru sebanyak 50\%; status gizi cukup 
sebanyak $80,6 \%$; ventilasi yang tidak memenuhi syarat sebanyak $63,9 \%$; kebiasaan merokok responden $\geq 6$ bulan sebanyak $77,8 \%$ dan peran tenaga kesehatan baik sebanyak 77,8\%. Pada hasil analisis bivariat ada hubungan yang bermakna antara status gizi dengan $\mathrm{p}=0,000$ dan $\mathrm{OR} 9,14$ kebiasaan merokok $\mathrm{p}=0.008$ dan $\mathrm{OR}$ 4.375 dan peran tenaga kesehatan $\mathrm{p}=$ 0,000 dengan OR 7000. dengan kejadian TB Paru. dan tidak ada hubungan yang bermakna antara ventilasi $\mathrm{p}=1,000$. dengan kejadian TB Paru. Status gizi kurang pada responden merupakan faktor yang paling dominan dengan kejadian TB Paru dengan peluang 9,4 kali untuk terjadinya kejadian TB Paru dibandingkan dengan status gizi responden yang cukup.

\section{REKOMENDASI}

DAFTAR PUSTAKA

Budi, A. S., \& Tuntun, M. (2013). Faktor-Faktor Yang Berhubungan Dengan Kejadian Tuberkulosis Paru BTA Positif Pada Pasien Rawat Jalan Di UPT Puskesmas Wonosobo Kabupaten Tanggamus Factors Associated To The Incidence Of Smear-Positive Pulmonary Tuberculosis In Outpatient In UPT Puskesmas. Jurnal Analis Kesehatan, 5(829), 566-573.

Dina Mariana, M. C. (2017).
Bagi responden kelompok kontrol diharapkan untuk meningkatkan pengetahuan dan pemahaman tentang upaya pencegahan penyakit Tuberkulosis paru dengan mengikuti kegiatan penyuluhan yang diberikan oleh tenaga kesehatan serta mengakses berbagai informasi tentang upaya pencegahan penularan penyakit.

Tuberkulosis paru melalui berbagai media. Dan kepada penderita Tuberkulosis paru agar lebih memperhatikan pola makan dengan makan sesuai kebutuhan zat gizi dan teratur, perbaikan kondisi ventilasi rumah agar memenuhi syarat kesehatan, dan menghindari kebiasaan merokok.

Petugas Kesehatan lebih meningkatkan peran terutama dalam penemuan kasus TB Paru yang sangat berhubungan dengan status gizi dari masyarakat.

\begin{tabular}{|c|c|}
\hline KEPADATAN & HUNIAN, \\
\hline VENTILASI & DAN \\
\hline PENCAHAYAAN & TERHADAP \\
\hline KEJADIAN TB & PARU DI \\
\hline WILAYAH & KERJA \\
\hline PUSKESMAS & BINANGA \\
\hline KABUPATEN & MAMUJU \\
\hline SULAWESI B & AT. Jurnal \\
\hline
\end{tabular}

Nurwanti, B. W. (2016). HUBUNGAN ANTARA FAKTOR PENJAMU ( HOST ) DANFAKTOR LINGKUNGAN ENVIRONMENT ) DENGAN KEJADIAN TUBERKULOSIS 
PARU KAMBUH ( RELAPS ) DI PUSKESMAS SE-KOTA SEMARANG Jurusan Ilmu Kesehatan Masyarakat Fakultas Ilmu Keolahragan Universitas Negeri semarang, Indone. Public Health Perspective Journal, 1(1), 77-87. https://doi.org/e-2540-7945 Rahmayuli, P., Lubis, D. M., Kedokteran, F., Muhammadiyah, U., Utara, S., Fisiologi, D., Utara, S. (2018). Hubungan Merokok dengan Hasil Pemeriksaan Bakteriologis Sputum pada. Buletin Farmaterra, 3(2), 88-96. https://doi.org/E.ISSN: 2528-410X

Ricardo, F., Heriyani, F., \& Khatimah, H. (2016). KEJADIAN TB PARU DI WILAYAH PUSKESMAS KELAYAN TIMUR. Buletin Berkala Kedokteran, 12(2), 279288.

Sari, R. P., \& Arisandi, R. D. (2018). ARTIKEL PENELITIAN Faktorfaktor yang Berhubungan dengan Kejadian Penyakit TB Paru di Wilayah Kerja Puskesmas Walantaka. Jurnal Ilmu Kesehatan Masyarakat, 07(01), 25-32.

Yuniar, I., \& Lestari, S. D. (2017). Hubungan Status Gizi dan Pendapatan Terhadap Kejadian
Tuberkulosis Paru. Skripsi, 1(1), 14-21.

Kementrian Kesehatan Republik Indonesia Direktorat Jenderal Pengendalian Penyakit dan Penyehatan Lingkungan. (2011). Pedoman Nasional Pengendalian Tuberkulosis.

Kementrian Kesehatan Republik Indonesia. (2015). Profil Dinas Kesehatan Provinsi Sumatera Barat Tahun 2015.

Kementrian Kesehatan Republik Indonesia. (2016). Profil Kesehatan Indonesia Tahun 2016.

Nurhidayah (2007). Hubungan antara karakteristik lingkungan rumah dengan kejadian Tuberkulosis (TB) pada anak di Kecamatan Paseh Kabupaten Sumedang. Diakses dari: ppjp.unlam.ac.id/journal/index.ph p/JDK/article/download/1649/142 3 pada tanggal 27 Juli 2018.

Maryani. (2015). Hubungan Tingkat Pengetahuan Petugas Kesehatan tentang Tubekulosis dengan Peranan Petugas Kesehatan dalam penemuan Suspek Tuberkulosis di Puskesmas Kartasura. Skripsi S1 Kesehatan Masyarakat. STIKes Kusuma Husada. 